\title{
Fertility awareness and attitudes towards parenthood among Danish university college students
}

Nina Olsén Sørensen ${ }^{1,2^{*}}$, Signe Marcussen ${ }^{3 *}$, Mette Grønbæk Backhausen ${ }^{1,4}$, Mette Juhl ${ }^{3,5}$, Lone Schmidt ${ }^{5}$, Tanja Tydén ${ }^{6}$ and Hanne Kristine Hegaard ${ }^{1,2}$

\begin{abstract}
Background: Postponing parenthood has steadily increased during the past decades in Western countries. This trend has affected the size of families in the direction of fewer children born per couple. In addition, higher maternal age is associated with an increased risk of pregnancy-related complications such as prematurity and foetal death, while higher paternal age increases the risk of miscarriage and affects time-to-pregnancy. Hence, understanding the circumstances and reflections that influence the decision is greatly needed and little is known about potential gender difference influencing the choice. The aim was to investigate attitudes towards parenthood, intentions for childbirth and knowledge about fertility issues among men and women.
\end{abstract}

Methods: We conducted a cross-sectional study based on a validated 49-item questionnaire among students, who attended selected mandatory lectures at a Danish university college in February to April 2016. The participation rate was 99\%, and 517 completed the questionnaire.

Results: Though the majority of all participants wished to have children in the future $(>86 \%)$, there was significant difference between the genders $(p=0.002)$. Women rated having children to be more important than men did $(p<0.001)$, while men rated higher the likelihood of abstaining from having children if faced with infertility $(p=0.003)$. Knowledge about fertility issues was similar between genders including poor knowledge about the age-related decline in female fertility. While women found it more important to have children before being 'too old' $(p=0.04$ ), still more than $40 \%$ of all respondents intended to have their last child after the age of 35 years. For both genders the most important prerequisite for parenthood was having a partner to share responsibility with. Perceived or experienced life changes related to parenthood were generally positive such as personal development.

Conclusion: The majority of respondents wished to have children, but many desired to have these after the biological decline in female fertility. The moderate knowledge level among both genders uncovered in this study is of concern. Future research should address the potential link between fertility knowledge and planning of parenthood. We may benefit from intervention studies examining the effect of routine preconception care.

Keywords: Postponed parenthood, Fertility awareness, Parenting attitudes, Questionnaire

\footnotetext{
*Correspondence: nina.olsen.soerensen@regionh.dk; sima@phmetropol.dk

'The Research Unit Women's and Children's Health, section 7821, The Juliane

Marie Centre for Women, Children and Reproduction, Copenhagen

University Hospital, Rigshospitalet, Blegdamsvej 9, 2100 Copenhagen,

Denmark

${ }^{3}$ Midwifery Program, Metropolitan University College, Sigurdsgade 26, 2200

Copenhagen, Denmark

Full list of author information is available at the end of the article
} 


\section{Plain English Summary}

During the past decades an increase in parental age has been seen in Western countries. This trend has affected the size of families in the direction of fewer children born per couple - in part due to the biological decline in fertility. Understanding what influences the decision to postpone pregnancy is greatly needed and little is known about potential gender difference influencing the choice. The aim was to investigate attitudes towards parenthood, intentions for childbirth and knowledge about fertility issues among both men and women.

We conducted a Danish questionnaire study in the period February to April 2016. The study population was 517 university college students and the participation rate was $99 \%$. The majority of these wished to have children in the future, but there was a significant difference between the genders. Women stated having children as being more important, while men were more likely to abstain from having children if faced with infertility. Knowledge about fertility issues was similar among both genders including poor knowledge about the age-related decline in female fertility. More than $40 \%$ intended to have their last child after the age of 35 years. The most important prerequisite for parenthood was having a partner to share responsibility with. Perceived or experienced life changes were generally positive such as personal development.

Good reproductive health starts before pregnancy and entails reflection about family planning and knowledge about fertility. Future research should address the potential link between fertility knowledge and planning of parenthood.

\section{Background}

During the past decades many countries have seen a marked increase in parental age $[1,2]$. In Denmark the age of first time fathers and mothers has increased by three and four years, respectively, since 1986 - resulting in a mean age of 31.3 years for men and 29.1 years for women in 2015 [3]. Similar trends are seen in other countries [1], and across the European Union first time mothers are oldest in Italy (30.6 years) and Spain (30.4 years) [4]. In the USA the proportion of mothers aged 35 years or older has steadily increased over the last 25 years, but the mean age of first time mothers is lower than in Europe (26.0 years in 2013) [5].

Advanced age of the mother, as well as the father, is known to be related to reduced fertility [6, 7], and the delay of parenthood seems to affect family size in the direction of fewer children born per couple [8]. Accordingly, a decline in total fertility rate (TFR) has been seen in OECD countries, where the average TFR dropped from 2.7 to 1.7 during the years 1970 to 2009 [9]. Higher maternal age is also associated with an increase in pregnancy-related complications and adverse outcome in the offspring [7] such as prematurity [10] and foetal death $[11,12]$. With regards to paternal age, studies have found an association with the general reproductive function such as prolonged time-to-pregnancy, and with pregnancy outcomes such as miscarriage [7]. Postponement of parenthood moreover implies that medically assisted reproduction (MAR) is a reality for a growing number of couples. However, the biological decline in fertility by advanced parental age cannot fully be compensated for by MAR [13], and consequently society as a whole is affected. Moreover, the psychological strain of undergoing fertility treatment should not be ignored [14]. A large Finnish register-based study found that infertile women who had received MAR-treatment, that did not result in a childbirth, had higher rates of hospitalizations for psychiatric diagnoses compared with MARtreated women, who did give birth [15].

The present study is a survey among university college students in Denmark. The fertility patterns in the Nordic welfare countries is quite similar. A demographic study covering national data from Denmark, Finland, Norway and Sweden on cohort fertility among women born in 1935 and later have shown similar patterns in the four countries regarding postponement of family formation and a recuperation in fertility levels at ages 30 and above in younger cohorts [16]. At 40 years of age women born in 1935 in the Nordic countries achieved on average 2.12.5 children, and women born in 1963 achieved on average 1.9-2.1 children [16]. Postponement of family formation was seen across all educational groups, however, the postponement was more pronounced among highly educated women [16]. In Denmark, in 2005 37-year old men had on average 1.5 children, and there were no differences in average number of children across educational groups. Among 35-year old women short-term educated women had on average 1.9 children compared to long-term educated women having on average 1.4 children [17]. Based on Danish national register data, since 2005 12-13\% of 50 -year old women are childless compared to $20-21 \%$ among men [18]. Based on register data it is not possible to discriminate between voluntarily childlessness and childlessness due to infertility. In Denmark, around 86\% of 30-39-year old fathers and $77 \%$ of mothers are at the labor market and 97\% of all 3-5 years old children are attending public day child care [19]. Danish parents have together up to 52 weeks of parental leave, whereof 32 weeks can be shared between the parents. In total, $37 \%$ of fathers use full/some part of the shared parental leave [20].

From a public health perspective and in the light of the abovementioned adverse medical and psychological consequences, the understanding of underlying factors for parenthood postponement warrants research and 
attention. Previous studies have uncovered several reasons including contemporary norms, the rise in access to and effectiveness of contraception, and an increase in women's level of education and labor market participation $[21,16]$. General lack of fertility knowledge, including the age-related decline in fertility, may also be a central and contributing factor [21-23]. While preconception care - comprising of counseling about fertility is not routinely provided in Denmark, recent campaigns run by the Danish National Health Authority [24] have addressed the issue of fertility awareness. However, the effect of these campaigns is not known. Another central issue is whether there are gender differences in fertility knowledge [22, 25].

\section{Aim}

The aim was to investigate attitudes towards parenthood, intentions for childbirth, and knowledge about fertility issues among male and female university college students.

\section{Methods}

We conducted a cross-sectional study in Copenhagen, Denmark, during a two-month period of February to April 2016. The Danish Data Protection Agency (j.nr: 2012-580004), as well as the administration at the Metropolitan University College, approved the study.

\section{Study population}

The study was carried out among male and female students enrolled in a full degree study program at the Metropolitan University College, Copenhagen, where a range of professional bachelor degree programs are offered (see Table 1). All of the 995 students registered to attend a mandatory module called the Inter-professional module were considered eligible. We chose to recruit from this module, because it was an ideal opportunity to engage students from all bachelor programmes and because of the recruitment convenience of large classroom or auditorium lectures.

\section{Procedure}

We recruited the students in continuation of a lecture, and one of three authors (NOS, SM and MJ) gave a brief oral introduction to the purpose of the study using layman terms. Students were asked to fill out a 15minute written questionnaire on attitudes towards parenthood, intentions for childbirth and knowledge about fertility issues. It was emphasized that participation was voluntary and anonymous, and that they could hand in a blank questionnaire. The use of aids, e.g. the internet, was discouraged. The questionnaires were handed out in envelopes and likewise collected immediately after being filled out. Among the 527 students present, 520 wanted to participate in the study leaving a participation rate of
99\%. Blank questionnaires $(n=3)$ were excluded from the data analysis leaving a final study population of 517.

\section{Questionnaire and study variables}

We used a questionnaire developed and pilot tested in a Swedish population and used in three studies on university students [22, 26, 27]. The instrument has shown good face validity and established internal consistency (Cronbach's alpha >0.7) [22]. Modified versions of the questionnaire have also been used among university students in North America and Ukraine [25, 28]. The questionnaire comprises of 49 items that can be grouped into seven categories:

1. Socio-demographic characteristics and reproductive history (ten items): Age, bachelor degree program, type of housing, own and parents' country of birth, relationship status, and own experience of pregnancy (yes/no).

2. Future intentions for childbirth (four items): Do you wish to have children? (yes/no). If the response was 'yes' three additional questions were posed: How many children do you want? At what age do you want/did you have your first child? At what age do you want/did you have your last child?

3. Importance of having children (one item): How important is it for you to have children? Response format was a visual analogue scale (VAS) (unimportant $=0 \mathrm{~cm}$, extremely important $=10 \mathrm{~cm}$ ).

4. Presumed behaviour in case of infertility (three items): What would you do if you and your partner could not get pregnant? Hereafter the participants were asked on a VAS to assess the likelihood of undergoing in vitro fertilization (IVF), adoption, or abstain from having children (entirely unlikely $=0 \mathrm{~cm}$, highly likely $=10 \mathrm{~cm}$ ).

5. Circumstances of importance for the decision to have children (13 items): Participant were asked to rate the importance of specific circumstances for their decision to become (or having become) a parent (see Fig. 1 for a comprehensive list). Response format was a Likert scale $(1=$ unimportant, $2=$ not very important, 3 = rather important, $4=$ important, $5=$ very important) and the possibility of answering no opinion.

6. Positive and negative perceived life changes related to parenthood (nine items): Participants were asked to assess to what extent they agreed with items specifying possible (or experienced) life changes in relation to parenthood (see Fig. 2 for comprehensive list). Response format was a Likert scale $(1=$ disagree, 2 = partially disagree, $3=$ mainly agree, $4=$ strongly agree, 5 = entirely) and the possibility of answering no opinion. 
7. Knowledge about fertility issues (nine items). This last category requested participants to answer questions about female age-related fertility, fecundity, and success odds for fertility treatment. The answer format was open-ended.

\section{Data analyses}

Descriptive statistics included prevalences and means with standard deviations (SD), and medians with range (minimum - maximum). In order to compare the differences in answers between male and female students for continuous data, such as VAS scores, we used Mann-Whitney $U$ test, as the data was not normally distributed. Pearson's chi-squared test was used for nominal variables. Statistical significance was defined as a two-sided $P$ value less than 0.05 . All statistical analysis was performed using SPSS 22.0 software (IBM).

\section{Results}

A total of 517 students answered the questionnaire, of these 79 men and 438 women. The socio-demographic characteristics and reproductive history are presented in Table 1. Mean age was 25.6 years among men and 24.2 years among women, and the majority of the participants were of Danish origin. Six out of ten reported to be in a steady relationship. A total of $9 \%$ of the men had children or were expecting children at the time of data collection. This was the case for $14 \%$ of the women (Table 1).

Table 2 shows that the majority of respondents, who did not have children at present $(n=453)$, wished this in the future (87\% among men and $97 \%$ among women). This constituted a statistically significant difference between the genders $(p=0.002)$. The majority wanted to have two children. Three fourths reported that the most desired age to have a first child was 25-29 years. While no men wished to have children before this age, $8 \%$ of the women did so. With regards to the last child, the desired age for the majority of men was higher than that of the women, in that $55 \%$ of the men wanted to have their last child after the age of 34 years compared to $41 \%$ of the women, but overall there was no significant difference.

When asked about the importance of having children, women regarded this as being significantly more important than the men $(p<0.001)$ (Table 3). Women were more likely to believe that they would undergo IVF treatment in case of fertility problems $(p<0.001)$, while men were more likely to think that they would abstain from having children $(p<0.003)$. Adoption was considered an equally possible option by both $(p=0.2)$ (Table 3).

As seen in Fig. 1, the circumstances assessed as 'important' or 'very important' for the decision to become a parent by most participants were: Having a partner to
Table 1 Socio-demographic characteristics and reproductive history of all study participants $(N=517)^{a}$

\begin{tabular}{|c|c|c|}
\hline & Men $(n=79)$ & Women $(n=438)$ \\
\hline Age (years) mean (SD) & $25.6(4.4)$ & $24.2(5.1)$ \\
\hline Range & $21-47$ & $18-58$ \\
\hline \multirow[t]{2}{*}{ Missing (n) } & 0 & 1 \\
\hline & n (\%) & n (\%) \\
\hline \multicolumn{3}{|l|}{ Bachelor degree program } \\
\hline Nursing & $10(13)$ & $186(42)$ \\
\hline Midwifery & 0 & $16(4)$ \\
\hline Physiotherapist & $19(24)$ & $33(7)$ \\
\hline Occupational Therapy & $6(8)$ & $26(6)$ \\
\hline Radiography & $6(8)$ & $14(3)$ \\
\hline Social work & $9(11)$ & $56(13)$ \\
\hline Biomedical Laboratory Sciences & $6(8)$ & $20(5)$ \\
\hline Global Nutrition and Health & $4(5)$ & $47(11)$ \\
\hline Emergency and Risk Management & $6(8)$ & 0 \\
\hline Business and Public Administration & $12(15)$ & $39(9)$ \\
\hline Missing & 1 & 1 \\
\hline \multicolumn{3}{|l|}{ Housing type } \\
\hline Student dormitory & $9(12)$ & $45(10)$ \\
\hline Living with parents & $6(8)$ & $46(11)$ \\
\hline Sublet Apartment & $15(19)$ & $97(22)$ \\
\hline Lodging & $15(19)$ & $66(15)$ \\
\hline Own apartment & $33(42)$ & $180(41)$ \\
\hline Other & 0 & $2(1)$ \\
\hline Missing & 1 & 2 \\
\hline \multicolumn{3}{|l|}{ Ethnicity } \\
\hline Born in Denmark & $71(90)$ & $386(88)$ \\
\hline One/both parents born in Denmark & $65(82)$ & $357(82)$ \\
\hline Missing & 0 & 2 \\
\hline \multicolumn{3}{|l|}{ Steady relationship } \\
\hline Yes & $47(60)$ & $270(62)$ \\
\hline Missing data & 1 & 2 \\
\hline \multicolumn{3}{|l|}{ Experienced pregnancy and outcome ${ }^{a}$} \\
\hline Had children & $6(8)$ & $47(11)$ \\
\hline Had abortion & $10(13)$ & $39(9)$ \\
\hline Experienced miscarriage & $2(3)$ & $11(3)$ \\
\hline Pregnant at present & $1(1)$ & $13(3)$ \\
\hline
\end{tabular}

aPercentages do not amount to 100 , as the participant may have experienced more than one of the given outcomes

share responsibility with, living in a stable relationship, and feeling sufficiently mature. Only approximately $1 \%$ listed friends planning/having children as an important issue. Significant differences between genders were seen for circumstances related to work and education, as more men than women rated having completed studies as 
Table 2 Future intentions concerning having children ${ }^{\mathrm{a}}(n=453)$

\begin{tabular}{|c|c|c|c|c|c|}
\hline & \multicolumn{2}{|c|}{ Men } & \multicolumn{2}{|c|}{ Women } & \multirow[t]{2}{*}{$P$} \\
\hline & $n$ & $\%$ & $n$ & $\%$ & \\
\hline \multicolumn{6}{|c|}{ Wish to have children } \\
\hline Yes & 59 & 87 & 354 & 97 & \multirow[t]{3}{*}{0.002} \\
\hline No & 9 & 13 & 12 & 3 & \\
\hline Missing & 4 & & 15 & & \\
\hline \multicolumn{6}{|l|}{ Desired number } \\
\hline 1 or $1-2$ & 2 & 4 & 23 & 7 & \multirow[t]{6}{*}{0.37} \\
\hline 2 & 26 & 46 & 126 & 37 & \\
\hline $2-3$ & 8 & 14 & 82 & 24 & \\
\hline 3 & 14 & 25 & 84 & 24 & \\
\hline $3-4$ or more & 6 & 11 & 28 & 8 & \\
\hline Missing & 16 & & 38 & & \\
\hline \multicolumn{6}{|c|}{ Desired age at first child } \\
\hline$\leq 24$ years & 0 & 0 & 26 & 8 & \multirow[t]{5}{*}{0.07} \\
\hline $25-29$ years & 35 & 75 & 252 & 77 & \\
\hline 30-34 years & 10 & 21 & 42 & 13 & \\
\hline$\geq 35$ years & 2 & 4 & 6 & 2 & \\
\hline Missing & 25 & & 55 & & \\
\hline \multicolumn{6}{|c|}{ Desired age at last child } \\
\hline$\leq 29$ years & 1 & 3 & 34 & 12 & \multirow[t]{5}{*}{0.21} \\
\hline 30-34 years & 15 & 42 & 134 & 47 & \\
\hline $35-39$ years & 16 & 44 & 100 & 35 & \\
\hline$>40$ years & 4 & 11 & 18 & 6 & \\
\hline Missing & 36 & & 95 & & \\
\hline
\end{tabular}

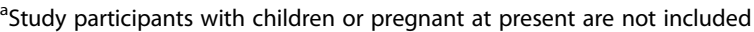

important $(p=0.003)$. The same was seen for having started a career (and being in a permanent job). Not being 'too old' was regarded an important circumstance by $52 \%$ of men and $64 \%$ of women ( $p=0.04)$ (Fig. 1).

When asked about perceived (or experienced) life changes in connection to becoming a parent, the most positively rated statement was personal development
(78\% men vs. $86 \%$ women) (Fig. 2). In addition, most participants stated that they 'strongly' or 'entirely' agreed that they would give and receive more love and that their relationship with partner would strengthen. While only $7 \%$ of men and $10 \%$ of women believed that having (or having had) children would negatively impact their status on the labor market, approximately one out of four thought it would affect their economy negatively. The only significant difference between men's and women's answers was related to the impact of parenthood on new interests in life $(p=0.04)$.

Table 4 shows that to questions on fertility knowledge answers were similar between the genders. Most participants answered correctly to women's most fertile age period. Half of both genders thought a slight age-related decline in female fertility has its onset beyond the age of 30 years (correct answer: 25-29 years). More than 35\% believed that a marked decrease does not occur until 40 years of age (correct answer: 35-39 years) - hereof more than $10 \%$ believed that this did not occur until 45 years. Both genders underestimated a couple's ability to conceive if having unprotected sex at the time of ovulation. However, in comparison with women, men were significantly more likely to underestimate fecundity at ovulation, when the woman was aged $35-40$ years $(p=$ 0.047 ). For the question on how many couples experience involuntary infertility the majority answered incorrectly and overestimated the probability of achieving a child from IVF treatment, in that $40 \%$ of the men and $46 \%$ of the women indicated chances to be $40-100 \%$.

\section{Discussion}

In this study most of the participants, who did not have children, stated that they wished to have children in the future. Women regarded having children as more important than men did. If faced with infertility men were more likely to believe that they would abstain from having children and less likely to believe they would pursue IVF treatment. A clear majority stated that having a partner to

Table 3 Importance of children and presumed behaviour in case of infertility ${ }^{a}$

\begin{tabular}{|c|c|c|c|c|c|c|c|}
\hline & \multicolumn{3}{|c|}{ Men } & \multicolumn{3}{|c|}{ Women } & \multirow[t]{2}{*}{$P$} \\
\hline & $n$ & median & SD & n & median & SD & \\
\hline Importance of children & 77 & 8.2 & 3.1 & 428 & 9.7 & 2.3 & $<0.001$ \\
\hline Missing & 2 & & & 10 & & & \\
\hline Undergo IVF & 74 & 6.4 & 3.4 & 427 & 8.9 & 2.7 & $<0.001$ \\
\hline Missing & 5 & & & 11 & & & \\
\hline Adoption & 74 & 5.6 & 2.0 & 423 & 5.3 & 3.1 & 0.2 \\
\hline Missing & 5 & & & 15 & & & \\
\hline Abstain from having children & 73 & 2.0 & 2.7 & 421 & 0.4 & 2.5 & 0.003 \\
\hline Missing & 6 & & & 17 & & & \\
\hline
\end{tabular}

${ }^{a}$ Responses given on a visual analogue scale. For question on importance: $0 \mathrm{~cm}=$ unimportant and $10 \mathrm{~cm}=$ extremely important, and for behavioural questions: $0 \mathrm{~cm}=$ entirely unlikely and $10 \mathrm{~m}=$ highly likely 


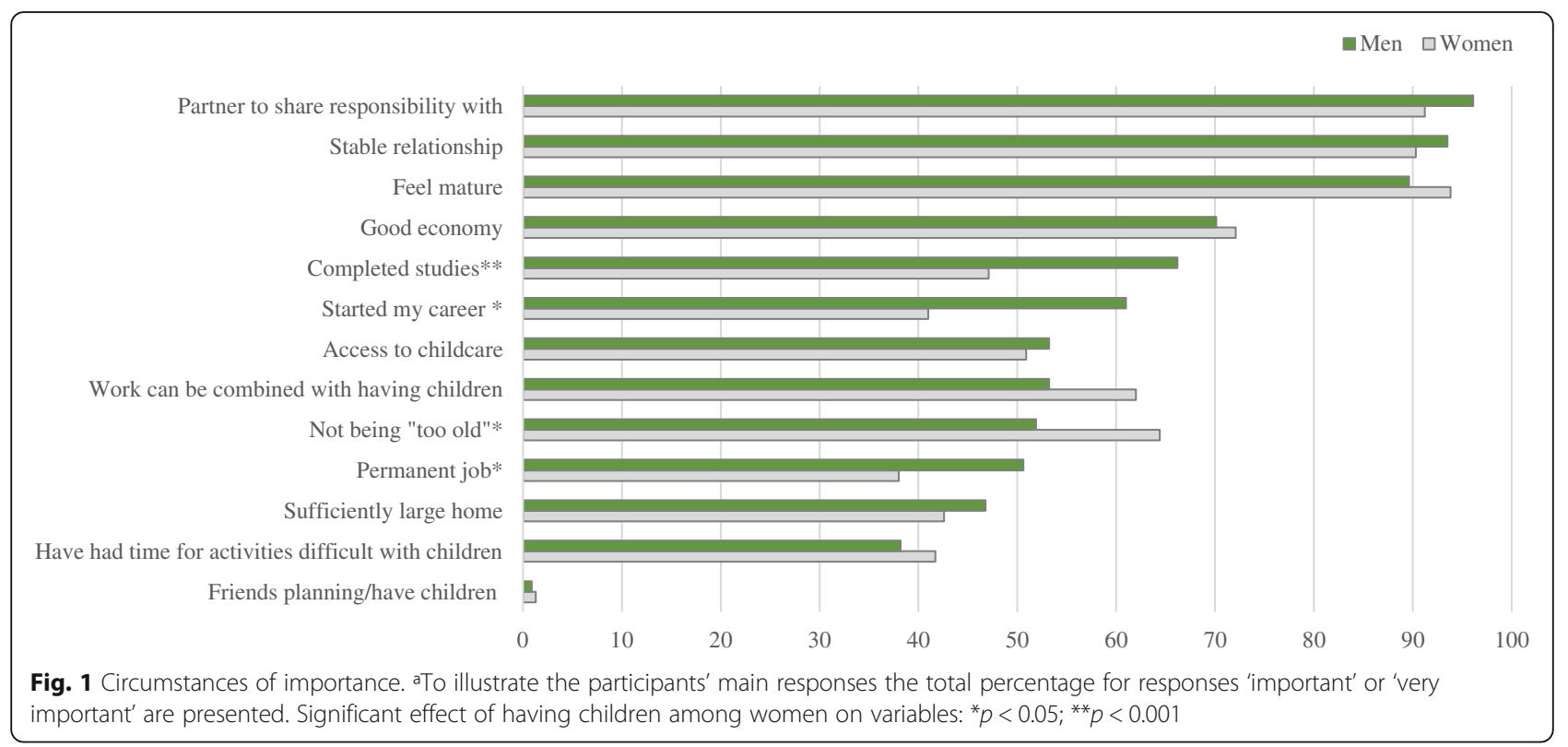

share responsibility with was the most important circumstance for parenthood. However, significantly more men than women wanted to have completed their studies, to have started a career, and to be in a permanent job position, before having children. Significantly more women found it important to have children before being 'too old'. Perceived (or experienced) life changes related to parenthood were overall positive, indicated by e.g. personal development, giving and receiving more love, and a stronger relationship with one's partner. Knowledge about fertility issues was similar among both genders. Most respondents thought that both the slight and marked decrease in fertility occurs later than it really does, and at the same time more than half overestimated the ability of IVF treatment.

Strengths of this study include that we used a questionnaire originally developed and validated in a comparable Scandinavian population of Swedish university students $[22,26,27]$. All of the questions on fertility knowledge were open-ended to minimize the risk of an overestimation of knowledge. Another strength is the high participation rate of $99 \%$. In addition, due to the sampling method, the random selection of respondents adds to the external validity. Unfortunately, those not present at the

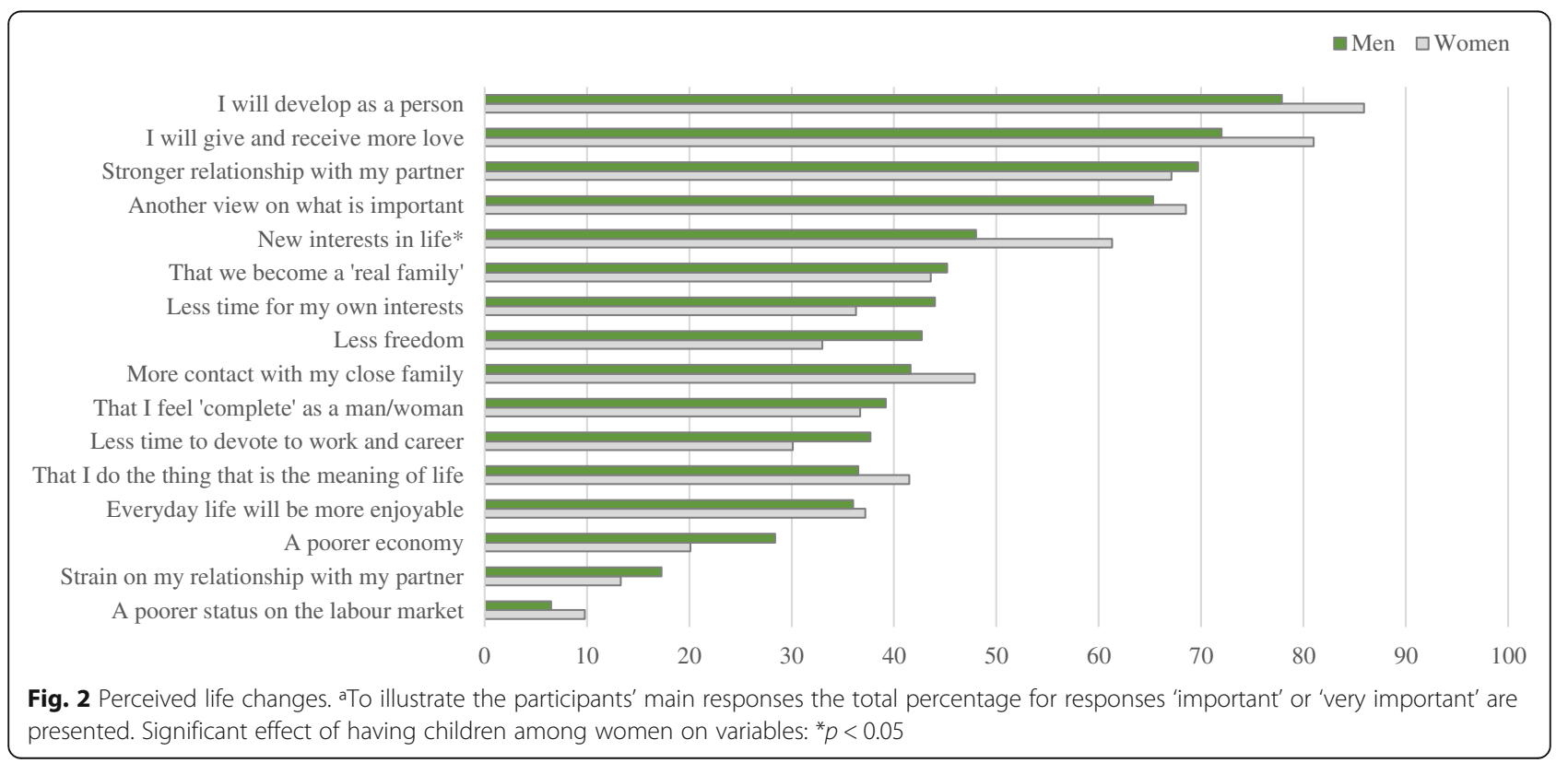


Table 4 Knowledge about fertility issues ${ }^{a}$

\begin{tabular}{|c|c|c|c|c|}
\hline Item & Categories & Men n (\%) & Women n (\%) & $P$ \\
\hline \multirow[t]{5}{*}{ At what age are women the most fertile? } & $15-19$ years & $17(23)$ & $67(15)$ & \multirow[t]{5}{*}{0.30} \\
\hline & $20-24$ years $^{\mathrm{a}}$ & $38(50)$ & $262(61)$ & \\
\hline & $25-29$ years & $20(26)$ & $94(22)$ & \\
\hline & $30-44$ years & $1(1)$ & $7(2)$ & \\
\hline & Missing & 3 & 8 & \\
\hline \multirow{5}{*}{$\begin{array}{l}\text { At what age is there a slight decrease in women's ability } \\
\text { to become pregnant? }\end{array}$} & $15-24$ years & $7(9)$ & $31(7)$ & \multirow[t]{5}{*}{0.07} \\
\hline & $25-29$ years $^{a}$ & $23(30)$ & $191(45)$ & \\
\hline & 30-34 years & $34(45)$ & $134(31)$ & \\
\hline & $35-59$ years & $12(16)$ & $72(17)$ & \\
\hline & Missing & 3 & 10 & \\
\hline \multirow{5}{*}{$\begin{array}{l}\text { At what age is there a marked decrease in women's ability } \\
\text { to become pregnant? }\end{array}$} & $25-34$ years & $20(26)$ & $139(33)$ & \multirow[t]{5}{*}{0.23} \\
\hline & $35-39$ years $^{a}$ & $22(29)$ & $134(31)$ & \\
\hline & 40-44 years & $20(26)$ & $108(25)$ & \\
\hline & $45-49$ years & $14(19)$ & $45(11)$ & \\
\hline & Missing & 3 & 12 & \\
\hline \multirow{5}{*}{$\begin{array}{l}\text { If a young woman and man have unprotected intercourse at } \\
\text { the time of ovulation - how large is the chance that she will } \\
\text { become pregnant? }\end{array}$} & $0-29 \%$ & $18(25)$ & $61(15)$ & \multirow[t]{5}{*}{0.06} \\
\hline & $30-39 \%{ }^{\mathrm{a}}$ & $8(11)$ & $29(7)$ & \\
\hline & $40-49 \%$ & $4(5)$ & $17(4)$ & \\
\hline & $50-100 \%$ & $43(59)$ & $310(74)$ & \\
\hline & Missing & 6 & 21 & \\
\hline \multicolumn{5}{|l|}{$\begin{array}{l}\text { If a woman and a man have regular unprotected intercourse } \\
\text { during a period of } 1 \text { year: }\end{array}$} \\
\hline \multirow[t]{5}{*}{ How large is the chance she will become pregnant if she is $25-30$ years? } & $0-69 \%$ & $35(47)$ & $182(45)$ & \multirow[t]{5}{*}{0.06} \\
\hline & $70-79 \%{ }^{\mathrm{a}}$ & $21(29)$ & $74(18)$ & \\
\hline & $80-89 \%$ & $9(12)$ & $98(24)$ & \\
\hline & $90-100 \%$ & $9(12)$ & $53(13)$ & \\
\hline & Missing & 5 & 31 & \\
\hline \multirow[t]{5}{*}{ How large is the chance she will become pregnant if she is $35-40$ years? } & $0-49 \%$ & $59(80)$ & $290(72)$ & \multirow[t]{5}{*}{0.047} \\
\hline & $50-59 \%^{a}$ & $8(11)$ & $57(14)$ & \\
\hline & $60-69 \%$ & $1(1)$ & $38(10)$ & \\
\hline & $70-100 \%$ & $6(8)$ & $17(4)$ & \\
\hline & Missing & 5 & 36 & \\
\hline \multirow[t]{5}{*}{ How many couples are involuntarily infertile? } & $0-4 \%$ & $1(1)$ & $6(2)$ & \multirow[t]{5}{*}{0.21} \\
\hline & $5-9 \%$ & $9(12)$ & $31(8)$ & \\
\hline & $10-19 \%^{\mathrm{a}}$ & $32(43)$ & $135(34)$ & \\
\hline & $20-90 \%$ & $33(44)$ & $226(56)$ & \\
\hline & Missing & 4 & 40 & \\
\hline \multirow[t]{5}{*}{ What are the chances on average of achieving a child from IVF treatment? } & $0-19 \%$ & $12(16)$ & $60(16)$ & \multirow[t]{5}{*}{0.82} \\
\hline & $20-29 \%^{a}$ & $21(29)$ & $96(25)$ & \\
\hline & $30-39 \%$ & $11(15)$ & $52(13)$ & \\
\hline & $40-100 \%$ & $29(40)$ & $175(46)$ & \\
\hline & Missing & 6 & 55 & \\
\hline
\end{tabular}

\footnotetext{
${ }^{a}$ Categories marked with asterix contain the correct answer
} 
time of recruitment, could not be approached and, thus, no background variables are available for this group. In accordance with the 995 students registered for the module, teachers stated that attendance was approximately $50 \%$. We do not know if non-participants potentially differ from students that attended lectures. In the present study only $15 \%(n=79)$ of the participants were male students and care should be taken not to draw statistical conclusions. However, the percentage of men correlates well with the overall gender distribution at the inter-professional module being approximately $17 \%$ according to the Metropolitan University College Study Administration. Finally, most students at the given inter-professional module came from health related programmes, indicating that knowledge gaps regarding fertility may be more pronounced among the overall student population in Denmark.

Missing data always warrants special attention [29]. In the present study some of the questions could be perceived as personal and consequently be left unanswered. In an effort to limit this possible source of bias the questionnaire was anonymized, and this was stressed to participants beforehand. Still we encountered varying degrees of missing data for specific questions e.g. desired age for last child ( $25 \%$ for women and $50 \%$ missing data for men). Nevertheless, in many instances the answer was actually not left blank, but respondents simply answered with a question mark, thus indicating they had not reflected on the answers. Therefore, we believe that the missing answers may be attributed to non-reflection. Still we cannot know if this has led to an under- or overestimation of our results.

In line with previous studies the majority of our respondents wished to have children in the future. Further, our data showed a statistically significant gender difference on this question. This is in line with a recent study from the Ukraine [28]. Also, consistent with previous studies female students rated the importance of having a child and the likelihood of undergoing IVF treatment higher than did their male co-students [22, 25]. One bold interpretation of these findings is that women generally value having children higher than men, but at the same time there is accordance between the desired number of children and age of first child across genders. No gender differences emerged regarding parental age at birth of last child, but more than $60 \%$ of the women (significantly more than the men) agreed it is important to have children before being 'too old'. A cautious interpretation of our results is that similarities and discrepancies between genders in their intentions for parenthood may interplay in the 'negotiation' about family planning within a couple and, thus, partly explain why parenthood is postponed.
In light of this interpretation Danish couples may benefit from tools like 'My Reproductive Life Plan' (RLP), recommended by the Centers for Disease Control and Prevention, and designed to help reflection on family planning matters [30, 31]. A Swedish randomized controlled trial study on RLP counseling found that the intervention strongly affected the age at which the participants wanted their last child [32]. The reflections encouraged by RLP may also refer to preconditions for parenthood e.g. work, studies, financial burden etc. In the present study the majority of high-scoring circumstances were related to creating the 'ideal environment' for having a child. Partner suitability was seen as highly important by both genders, which is mimicked by several other studies $[22,26,28]$. Still, men rated circumstances related to studies and work when making the decision to have children significantly higher than the women did. Another aspect is, that even though $86 \%$ of $30-39$-year old fathers and $77 \%$ of mothers are in the labor market [19], only $50 \%$ of both men and women in our study reported access to childcare as an important or very important factor in the decision on having children. Explanations for this may be that parents are entitled to a combined parental leave of up to 52 weeks [20], and a total of $97 \%$ of all 3-5 year old children attend public daycare [19].

Previously published literature has compared men's and women's knowledge about fertility [22, 25, 26, 32, 33]. Some studies found that men overall had less knowledge about fertility $[22,25,34]$, which is in line with the conclusion from Bunting et al., who investigated several knowledge areas including basics facts about infertility and indicators for reduced fertility [23]. In our study the participants generally lacked knowledge on fertility issues, but there were no substantial differences between the two genders.

The probability of pregnancy from unprotected intercourse in a young couple at the time of ovulation and the success rate of MAR were grossly overestimated by both groups [35]. Furthermore, more than half the participants answered incorrectly to female age at which a marked decrease in fertility is seen. Other studies have time and again found similar limited knowledge among university students $[22,25,28,36]$. This is of particular concern, as a sizable percentage of respondents intend to have their last child at the age of 35 years or older, where a marked decline in female fertility is a reality [37]. The fact that many participants lacked knowledge on fertility raises concern and may indicate that both men and women are making the decision to postpone parenthood without being aware of possible consequences. Adding to this concern, the majority of participants stated wanting two children, but the current reproduction rate in Denmark is 1.69 [18] showing a potential disparity between what is desired and the actual outcome. The interaction 
between fertility knowledge and family intentions is not well documented, but a recent European study found that women, who under-estimated the impact of age on fertility, desired to have their first child at a higher age [34]. More studies are needed to confirm these results, but the necessity of fertility education on the 'optimal' timing of parenthood seems evident.

\section{Conclusion}

The present study provides insight into contemporary attitudes towards parenthood and knowledge about fertility issues among Danish university college students. The majority of male and female respondents wished to have children and they had an overall positive attitude towards perceptions of parenthood. Many reported that they wished to have children at an age, where the biological decline in female fertility has set in, and there was a general lack of knowledge about fertility issues. Our findings indicate a need for additional information and counselling such as RLP to the younger populations in Denmark. RLP has shown to be useful to increase knowledge and awareness of reproductive health [30-32]. Our data did not indicate any strong associations between gender and knowledge about fertility. Future research should address the potential link between fertility knowledge and planning of parenthood, and we may benefit from intervention studies examining the effect of offering preconception care. Also, the authors suggest similar cross-sectional studies carried out in settings with larger proportions of male students and that does not have a focus on health related subjects.

\section{Abbreviations}

IVF: In vitro fertilization; MAR: Medically assisted reproduction; RLP: 'My Reproductive life-plan'; VAS: Visual analogue scale

\section{Acknowledgements}

We would like to acknowledge midwifery students K. Søndberg and S. Bisgaard, as well as midwife M. Tardini, for their assistance with data entry. Furthermore, we would like to extend a big thank you to all the students and educators of Metropolitan University College, for their time and participation.

\section{Funding}

No funding was awarded this study.

\section{Availability of data and materials}

All supporting data, on which the results in this study build, can be obtained by contacting the corresponding author.

\section{Authors' contributions}

$\Pi$ was part of the group that developed the original questionnaire and $\Pi$, HH, LS and NOS designed the present study. MJ, HH, NOS and SM planned the study, while HH, SM, NOS, MB, MJ collected the data. HH, NOS and LS were involved in the compilation of the results in cooperation with all coauthors. NOS, HH and MB drafted the manuscript. All authors read, critically revised and approved the final manuscript.

\section{Competing interest}

The authors declare that they have no competing interests.

\section{Ethics approval and consent to participate}

The Danish Data Protection Agency (j.nr: 2012-58-0004), as well as the administration at the Metropolitan University College, approved this study. In accordance with Danish legislation approval from the Ethics

Committee was not required.

\section{Author details}

'The Research Unit Women's and Children's Health, section 7821, The Juliane Marie Centre for Women, Children and Reproduction, Copenhagen University Hospital, Rigshospitalet, Blegdamsvej 9, 2100 Copenhagen, Denmark. ${ }^{2}$ Department of Obstetrics, Copenhagen University Hospital, Rigshospitalet, Blegdamsvej 9, 2100 Copenhagen, Denmark. ${ }^{3}$ Midwifery Program, Metropolitan University College, Sigurdsgade 26, 2200 Copenhagen, Denmark. ${ }^{4}$ Department of Gynecology and Obstetrics, Zealand University Hospital, Syghusvej 10, 4000 Roskilde, Denmark. ${ }^{5}$ Department of Public Health, University of Copenhagen, Øster Farimagsgade 5, 1014 Copenhagen, Denmark. ${ }^{6}$ Department of Women's and Children's Health, Uppsala University, Akademiske Sjukhuset, SE-751 85 Uppsala, Sweden.

Received: 5 July 2016 Accepted: 23 November 2016

Published online: 13 December 2016

\section{References}

1. Schmidt L, Sobotka T, Bentzen JG, Nyboe Andersen A, ESHRE Reproduction and Society Task Force. Demographic and medical consequences of the postponement of parenthood. Hum Reprod Update. 2012;18(1):29-43.

2. Sobotka T. Is Lowest-Low Fertility in Europe Explained by the Postponement of Childbearing? Popul Dev Rev. 2004;30(2):195-220.

3. Statistics Denmark: Average age og first time mothers (1986-2015) [Internet] Available from: http://statistikbanken.dk/fod11. Accessed 2 May 2016.

4. Eurostat [Internet]. Available from: http://ec.europa.eu/eurostat/web/ products-datasets/-/demo_fordager. Accessed 2 May 2016.

5. Martin. National Vital Statistics Reports. Births: Final Data for 2013 [Internet]. Available from: http://www.cdc.gov/nchs/data/nvsr/nvsr64/nvsr64_01.pdf. Accessed 9 May 2016

6. Balasch J, Gratacós E. Delayed childbearing: effects on fertility and the outcome of pregnancy. Curr Opin Obstet Gynecol. 2012;24(3):187-93.

7. Sartorius GA, Nieschlag E. Paternal age and reproduction. Hum Reprod Update. 2010;16(1):65-79.

8. Morgan SP, Rackin $\mathrm{H}$. The correspondence between fertility intentions and behavior in the United States. Popul Dev Rev. 2010;36(1):91-118.

9. Organisation for Economic Co-operation and Development, OECD iLibrary, editor. Doing better for families. Paris: OECD; 2011. p. 275.

10. Delbaere I, Verstraelen H, Goetgeluk S, Martens G, De Backer G, Temmerman M. Pregnancy outcome in primiparae of advanced maternal age. Eur J Obstet Gynecol Reprod Biol. 2007:135(1):41-6.

11. Silver RM. Fetal death. Obstet Gynecol. 2007;109(1):153-67.

12. Kenny LC, Lavender T, McNamee R, O'Neill SM, Mills T, Khashan AS. Advanced Maternal Age and Adverse Pregnancy Outcome: Evidence from a Large Contemporary Cohort. Shi Q, editor. PLoS ONE. 2013. 20:8(2):e56583.

13. Leridon $\mathrm{H}$. Can assisted reproduction technology compensate for the natural decline in fertility with age? A model assessment. Hum Reprod. 2004;19(7):1548-53.

14. Schmidt L. Social and psychological consequences of infertility and assisted reproduction-what are the research priorities? Hum Fertil. 2009:12(1):14-20.

15. Yli-Kuha A-N, Gissler M, Klemetti R, Luoto R, Koivisto E, Hemminki E. Psychiatric disorders leading to hospitalization before and after infertility treatments. Hum Reprod. 2010;25(8):2018-23.

16. Andersson G, Rønsen M, Knudsen LB, Lappegård T, Neyer G, Skrede K, et al. Cohort fertility patterns in the nordic countries. Demogr Res. 2009;20:313-52.

17. Knudsen LB. Fertilitetsudviklingen [Fertility, in Danish]. In: Fertilitet og sundhed [Fertility and health, in Danish]. Copenhagen; 2012. p. 15-38.

18. Danmarks Statistik. Befolkningens udvikling $2014=$ Vital statistics 2014. Kbh; 2016

19. Statistics Denmark. Kvinder \& Mænd [Women \& men, in Danish]. Copenhagen: Statistics Denmark; 2011.

20. Statistics Denmark. Social transfer and childbirth [Dagpenge ved fødsel, in Danish]. News from Statistics Denmark number 148. 2015.

21. Mills $M$, Rindfuss RR, McDonald P, te Velde $E$, on behalf of the ESHRE Reproduction and Society Task Force. Why do people postpone parenthood? Reasons and social policy incentives. Hum Reprod Update. 2011;17(6):848-60 
22. Lampic C. Fertility awareness, intentions concerning childbearing, and attitudes towards parenthood among female and male academics. Hum Reprod. 2005;21(2):558-64.

23. Bunting L, Tsibulsky I, Boivin J. Fertility knowledge and beliefs about fertility treatment: findings from the International Fertility Decision-making Study. Hum Reprod. 2013;28(2):385-97.

24. Sundhedsstyrelsen, Miljø- og Fødevarestyrelsen. MaybeBaby - oplysningskampagne om fertilitet [Internet]. Available from: http://maybebaby.dk/. Accessed 14 June 2016.

25. Peterson BD, Pirritano M, Tucker L, Lampic C. Fertility awareness and parenting attitudes among American male and female undergraduate university students. Hum Reprod. 2012;27(5):1375-82.

26. Skoog Svanberg A, Lampic C, Karlström P-O, Tydén T. Attitudes toward parenthood and awareness of fertility among postgraduate students in Sweden. Gend Med. 2006:3(3):187-95.

27. Tydén T, Svanberg AS, Karlström P-O, Lihoff L, Lampic C. Female university students' attitudes to future motherhood and their understanding about fertility. Eur J Contracept Reprod Health Care. 2006;11(3):181-9.

28. Mogilevkina I, Stern J, Melnik D, Getsko E, Tydén T. Ukrainian medical students' attitudes to parenthood and knowledge of fertility. Eur J Contracept Reprod Health Care. 2016;22:1-6.

29. Kang $\mathrm{H}$. The prevention and handling of the missing data. Korean J Anesthesiol. 2013;64(5):402.

30. Centers for Disease Control and Prevention. Preconception Health and Health Care [Internet]. Available from: http://www.cdc.gov/preconception/ reproductiveplan.html. Accessed 13 June 2016.

31. Johnson K, Posner S, Biermann J, Cordero J, Atrash H, Parker C, et al. Recommendations to Improve Preconception Health and Health Care -United States. A report of the CDC/ATSDR Preconception Care Work Group and the Select Panel on Preconception Care. CDC; 2006. p. 1-23. Report No.: 55.

32. Stern J, Larsson M, Kristiansson P, Tyden T. Introducing reproductive life plan-based information in contraceptive counselling: an RCT. Hum Reprod. 2013;28(9):2450-61.

33. Daniluk JC, Koert E. Fertility awareness online: the efficacy of a fertility education website in increasing knowledge and changing fertility beliefs. Hum Reprod. 2015;30(2):353-63.

34. Vassard D, Lallemant C, Nyboe Andersen A, Macklon N, Schmidt L. A population-based survey on family intentions and fertility awareness in women and men in the United Kingdom and Denmark. Ups J Med Sci. 2016;27:1-8.

35. The European IVF-monitoring programme (EIM), for the European Society of Human Reproduction and Embryology (ESHRE). Assisted reproductive technology in Europe, 2001. Results generated from European registers by ESHRE. Hum Reprod. 2005;20(5):1158-76.

36. Chan CHY, Chan THY, Peterson BD, Lampic C, Tam MYJ. Intentions and attitudes towards parenthood and fertility awareness among Chinese university students in Hong Kong: a comparison with Western samples. Hum Reprod. 2015;30(2):364-72.

37. Dunson DB. Changes with age in the level and duration of fertility in the menstrual cycle. Hum Reprod. 2002;17(5):1399-403.

\section{Submit your next manuscript to BioMed Central and we will help you at every step:}

- We accept pre-submission inquiries

- Our selector tool helps you to find the most relevant journal

- We provide round the clock customer support

- Convenient online submission

- Thorough peer review

- Inclusion in PubMed and all major indexing services

- Maximum visibility for your research

Submit your manuscript at www.biomedcentral.com/submit
Biomed Central 